REVISTA DE DERECHO UNED, NÚM. 10, 2012

\title{
¿PODRÍA INSTAURARSE UNA JURISDICCIÓN VOLUNTARIA PENAL?*
}

\author{
SONIA CALAZa LóPEZ \\ Profesora Titular de Derecho Procesal. Universidad Nacional de \\ Educación a Distancia
}

Resumen: En este trabajo, que constituye la continuación de otros anteriores sobre diversos aspectos de esta misma temática, nos cuestionamos si sería posible y conveniente instaurar, en nuestro vigente ordenamiento procesal, una Jurisdicción Voluntaria Penal, merced a la cual, en sintonía con los futuros procesos civiles de naturaleza no jurisdiccional que integrarán la inminente Ley de Jurisdicción Voluntaria, pudiera otorgarse, a un operador jurídico, distinto al órgano de enjuiciamiento, la solución del conflicto, mediante una "privatización» de nuestra Justicia penal, en los casos de faltas y delitos de baja intensidad o escaso reproche social.

Asimismo, nos preguntarnos, en los procedimientos que fueren de naturaleza jurisdiccional, si cabría, en virtud del supuesto «principio de oportunidad» otorgar a los órganos de acusación la facultad discrecional de incoar o no, así como, en su caso, de mantener o suspender el proceso penal, en aquél tipo de faltas y delitos bagatela, conforme a criterios discrecionales.

Ante la imposibilidad de acometer, en un trabajo de estas características espaciales, una enumeración exhaustiva de la totalidad de actuaciones que integrarían, caso de admitirse, esa supuesta «Jurisdicción Voluntaria Penal», centraremos el objeto de este breve ensa-

* Este trabajo ha sido realizado en el marco del Proyecto de investigación «Stop Hate Crimes in Europe», Programa Justicia Penal, Dirección General de Justicia, Libertad y Seguridad de la Comisión Europea, con referencia JLS/2009/JPEN/AG.

(C) UNED. Revista de Derecho UNED, núm. 10, 2012 
yo en el estudio general del «principio de oportunidad» y su posible proyección sobre las actuaciones de los órganos de acusación y enjuiciamiento en el marco del proceso penal, dejando pendiente, para publicaciones posteriores, la reflexión sobre su posible alcance en el ámbito no jurisdiccional.

Abstract: In this work, which constitutes the continuation of previous others on other aspects of the same subject matter, we question ourselves if it would be possible, to restore in our in force procedural classification, a Voluntary Penal Jurisdiction, mercy to which, in tuning in with the future civil procedures of not jurisdictional nature that will integrate the imminent Law of Voluntary Jurisdiction, the solution of the conflict could be granted, to a juridical operator, different from the organ of prosecution, by means of a "privatization» of our penal Justice, in the cases of lacks and crimes of low intensity or scanty social reproach.

Likewise, us to wonder, in the procedures that will be of jurisdictional nature, if it would be necessary, by virtue of supposed «beginning of opportunity» to grant to the organs of accusation the discretionary faculty of incoar or not, as well as, in his case, of supporting or suspending the penal process, in that one type of lacks and crimes trifle, in conformity with discretionary criteria.

Before the inability to attack, in a work of these spatial characteristics, an exhaustive enumeration of the totality of actions that would integrate, I marry of be admitting, this supposed «Voluntary Penal Jurisdiction", we will centre the object of this brief test on the general study of the «beginning of opportunity» and his possible projection on the actions of the organs of accusation and prosecution on the frame of the penal process, leaving earring, for later publications, the reflection on his possible scope in the not jurisdictional area.

Palabras Clave: Jurisdicción Voluntaria Penal, principio de oportunidad, privatización de la justicia penal.

Key words: Voluntary Penal Jurisdiction, beginning of opportunity, privatization of our penal Justice.

Sumario: Introducción. I. Conceptualización jurídica, lógica e ius-filosófica de la «oportunidad». II. Ámbito de aplicación. III. Reflexiones generales sobre la conveniencia de la instauración de una Jurisdicción Voluntaria Penal. 1. En los procesos de naturaleza no jurisdiccional. 2. En los procesos de naturaleza jurisdiccional. Bibliografía. 


\section{INTRODUCCIÓN}

La lentitud, carestía e ineficacia de nuestro vigente proceso penal ha impulsado, a un buen número de jueces, magistrados, fiscales, procesalistas y penalistas, en general, a manifestarse a propósito de la urgente necesidad de regular medidas complementarias o alternativas a nuestro actual sistema procesal, que procuren una agilización de la Justicia, sin merma de garantías, todas ellas, de algún modo, relacionadas, con el denominado "principio de oportunidad», así, entre otras, las relativa a la «negociación del conflicto penal», mediante la potenciación de la conformidad y de la mediación, así como de la «posible»-o «imposible»-, de ello trataremos en el presente ensayo -disposición, por parte de los órganos de acusación, del ejercicio de la acción penal y del mantenimiento de la pretensión conforme a parámetros discrecionales.

La polémica surgida a propósito de la posible introducción del principio de la autonomía de la voluntad, en los procesos penales, caracterizados, desde el albur de los tiempos, por su sometimiento al más estricto principio de legalidad, nos induce a preguntamos si, en efecto, sería posible, instaurar en nuestro vigente ordenamiento procesal, una Jurisdicción Voluntaria Penal, merced a la cual, en sintonía con los futuros procedimientos civiles de naturaleza no jurisdiccional que integrarán la inminente Ley de Jurisdicción Voluntaria ${ }^{1}$, pudiera

${ }^{1}$ Para un estudio pormenorizado y de conjunto sobre la nueva «Jurisdicción Voluntaria», se remite al lector al máximo exponente en la materia, FERNÁNDEZ DE BUJÁN, A.. Podrían citarse casi un centenar de trabajos -en la bibliografía de este ensayo se recogen los más relevantes-, pero he de conformarme, en este breve espacio, con citar los siguientes: "Jurisdicción Voluntaria en Derecho Romano», Ed. Reus, 1986, $3^{\text {a }}$ ed., 1999.; «A propósito de la competencia en materia de iurisdictio voluntaria en Derecho Romano», Revista de Derecho Notarial, 1987; «Diferencias entre los actos de iurisdictio contenciosa y iurisdictio voluntaria en Derecho Romano", en Estudios Homenaje a A. D’ors, vol. I, Pamplona, 1987; "Consideraciones acerca del carácter clásico y jurisdiccional de la denominada por Marciano «Iurisdictio voluntaria», en D. 1.16.2. pr. Estudios homenaje a J. Iglesias, Madrid, 1987; «La jurisdicción voluntaria en la encrucijada: su conexión con el nuevo modelo procesal de la LEC del año 2000», revista de Derecho y opinión, Córdoba, 2000; «Los principios informadores de la jurisdicción voluntaria: una propuesta de futuro», Anuario de Derecho de la U.A.M., vol. 5, 2001; Jurisdicción Voluntaria: naturaleza jurídica y diferencias de procedimiento con la jurisdicción contenciosa», Actualidad Civil, no 36, 2001; «Consideraciones de lege ferenda en materia de jurisdicción voluntaria y Anteproyecto de Jurisdicción Voluntaria», Revista del Colegio de Abogados de Lugo, 2001 y 2002; "La jurisdicción voluntaria: racionalización y redistribución de competencias», en Libro Homenaje a Sánchez Mera, Madrid, 2002; «La Jurisdicción Voluntaria: una reforma legislativa pendiente». Estudios Jurídicos. Ministerio de Justicia, vol. IV, 2002; «Noción de iurisdictio y etapas. Jurisdicción contenciosa y jurisdicción voluntaria», 
otorgarse, a un operador jurídico, distinto al órgano de enjuiciamiento, la solución del conflicto penal, mediante una "privatización» de nuestra Justicia penal, en los casos de faltas y delitos de baja intensidad o escaso reproche social. Asimismo, hemos de preguntarnos, en los procedimientos que fueren de naturaleza jurisdiccional, si cabría, en virtud del supuesto «principio de oportunidad» otorgar a los órganos de acusación la facultad discrecional de incoar o mantener el proceso penal, en aquél tipo de faltas y delitos bagatela.

Ante la imposibilidad de acometer, en un trabajo de estas características espaciales, una enumeración exhaustiva de la totalidad de actuaciones que integrarían, caso de admitirse, esa supuesta «Jurisdicción Voluntaria Penal», centraremos el objeto de este breve ensayo en el estudio "principio de oportunidad» y su posible proyección sobre las actuaciones de los órganos de acusación y enjuiciamiento en el marco del proceso penal, dejando pendiente, para publicaciones posteriores, la reflexión sobre su posible alcance en el ámbito no jurisdiccional.

\section{CONCEPTUALIZACIÓN JURÍDICA, LÓGICA E IUS- FILOSÓFICA DE LA «OPORTUNIDAD»}

A la hora de abordar el estudio de este supuesto «principio de la oportunidad», debemos preguntarnos, en primer lugar, si la noción de «principio» puede, en verdad, aplicarse a la «oportunidad», y ello debido a la circunstancia de que lo «oportuno», por definición, no se puede generalizar, teniendo siempre por objeto lo casual, lo particular o lo excepcional. Si lo "casuístico» no es susceptible de ser definido sino atendiendo al «caso concreto», no podríamos hablar, en pu-

Portal electrónico de Derecho, IUSTEL, 2002; «La reforma legislativa de la jurisdicción voluntaria: reflexiones de presente y perspectivas de futuro», en «Jurisdicción Voluntaria: Historia (I), Problemas (II), Interrogantes (III) y Soluciones (IV)», Tribuna Pública, Marcados, Voz de Galicia, 12-9, 19-9, 26-9 y 3-10-2004; «Jurisdicción y arbitraje en Derecho Romano», Ed. Iustel, $1^{\mathrm{a}}$ ed., Madrid, 2006; «El nuevo perfil de la jurisdicción voluntaria en el Anteproyecto de Ley de octubre de 2005 (De la tutela de relaciones jurídicas privadas a la protección de intereses generales, públicos o sociales)», La Ley n ${ }^{\circ} 6500,8$ de junio de 2006; «Hacia una Teoría general de la Jurisdicción Voluntaria», volumen I, Ed. IUSTEL, Madrid, 2007; «Hacia una Teoría general de la Jurisdicción Voluntaria», volumen II, Ed. IUSTEL, Madrid, 2008; «Derecho Público Romano», Ed. Civitas, 13 ${ }^{\mathrm{a}}$ ed., Madrid, 2010; «Derecho Privado Romano», Ed. Civitas, Madrid, 2010; «La Jurisdicción Voluntaria en el plató», Revista del Colegio Notarial de Madrid no 41, enero-febrero, 2012. 
ridad, tal y como hemos concluido en trabajos anteriores a éste ${ }^{2}$, de un principio general o absoluto, ni mucho menos de un principio de principios, jerárquicamente superior al resto de los principios y menos, desde luego, en el ámbito penal.

Lo oportuno -el kairós- es el juicio realizado en razón del caso concreto y, por tanto, no se puede generalizar bajo la forma de un principio ni de una regla. La generalización de lo oportuno, bajo la forma de la oportunidad-cuya posible aplicación ha de ser siempre limitativa y excepcional- conduciría inevitablemente a una actuación arbitraria, proscrita por el «principio de interdicción de la arbitrariedad de los poderes públicos»${ }^{3}$.

En la medida en que un principio, por definición, da razón de un género determinado de cosas, y la razón de la oportunidad es extraída del caso concreto, no pudiendo nunca generalizarse, no cabe atribuir a la oportunidad un carácter genérico o reglado, ni mucho menos la razón principal de una regla o norma.

De hecho, la eventual legislación de «casos concretos» generaría una gran inseguridad jurídica, además de una arbitrariedad. De ahí que la «oportunidad» no pueda asumir un carácter general o reglado, su única realidad se la da el caso concreto.

Puesto que todo principio, en tanto que tal, es causa de lo que viene después, la oportunidad, no siendo principio, no tiene por objeto lo «causal»-menos aún la causa eminente que es precisamente lo que define la noción de principio-, sino lo «casual» o lo oportuno en el seno de la causa. Así, mientras que la «causa» ordena, lo «casual» excepciona. Luego, una normativa sustentada en «lo casual» convertiría el proceso judicial en un proceso excepcional -y, por ende, el estado de derecho en un estado de excepción, prototipo de los regímenes fascistas- caracterizado por una sucesión «casual» de actuaciones, sin un principio general o reglado que informase ese procedimiento.

Los procesalistas que se han ocupado, con distinto criterio al respecto, de esta cuestión han partido del sostenimiento de la existencia

${ }^{2}$ Un estudio más amplio y detallado, puede consultarse en CALAZA LÓPEZ, S., ¿Es realmente un principio la oportunidad?, Actualidad Jurídica Aranzadi no 842, mayo, 2012.

${ }^{3}$ Vid., sobre esta temática, CALAZA LÓPEZ, S., «De la arbitrariedad administrativa, con especial referencia al ámbito penal», Madrid, Revista de Derecho, UNED, núm. 4, 2009 y CALAZA LÓPEZ, S., «Recepción de la noción arbitrariedad en la Jurisdicción contencioso-administrativa española», Madrid, Revista de Derecho UNED $\mathrm{n}^{\circ} 7,2010$. 
de un sistema procesal regido por el «principio de oportunidad» cuando los órganos de persecución penal (Ministerio Fiscal y Policía) estuvieren expresamente autorizados, ante delitos que no revisten especial gravedad, para no instar el proceso penal o, en su caso, para provocar el sobreseimiento de la instrucción, atendiendo a razones tales como la escasa lesión social, la reparación del daño, la economía procesal o la rehabilitación del delincuente.

Por el contrario, en un sistema procesal regido por el «principio de legalidad»-al que nuestra doctrina procesal moderna atribuye un carácter antagónico respecto del supuesto principio de la «oportunidad»- la autoridad encargada del sostenimiento de la pretensión penal no está legitimada para abandonarla en tanto persistan los presupuestos materiales que la han provocado ${ }^{4}$.

Frente a los autores partidarios de conferir al MF, en virtud de la «oportunidad» un papel director del proceso penal, gozando del monopolio, en determinados supuestos, tanto del ejercicio de la acción, como del mantenimiento de la pretensión, se alzan quiénes entienden que "disminuir el poder de un órgano independiente, como son los jueces y magistrados, para aumentar el poder de un órgano subordinado al Poder Ejecutivo, como es el Ministerio Público», mediante la concesión de una «facultad más o menos discrecional (oportunidad sin más u oportunidad reglada) -para 1.) bien no ejercitar la acción penal; 2.) bien pedir que se imponga al acusado una pena distinta o inferior a la prevista legalmente; o 3.) bien concluir el proceso sin que en el mismo llegue a dictarse sentencia condenatoria)», supone necesariamente la «perversión de todo el sistema material penal $»^{5}$.

Si el criterio de la oportunidad se puede subordinar al principio de legalidad en el ámbito penal, entonces podría aceptarse, a nuestro entender, su aplicación discrecional, pero nunca podría asumirse, por las razones anteriormente expuestas, su preferencia, prevalencia o prioridad frente a un principio fundamental.

Una vez establecidos estas reflexiones generales a propósito de la imposibilidad de calificar a la «oportunidad» como un principio ge-

${ }^{4}$ Vid., en este sentido, GIMENO SENDRA, V., «Los procedimientos penales simplificados. Principio de oportunidad y proceso penal monitorio», Poder Judicial, $\mathrm{n}^{\circ}$ especial II, Madrid, 1988, págs. 34 y 35.

5 Vid., a este respecto, MONTERO AROCA, J., «Principios del proceso penal. Una explicación basada en la razón», Ed. Tirant lo blanch, Valencia, 1997, págs. 73, 78 y 79 , respectivamente. 
neral, nuclear o rector del proceso penal ${ }^{6}$, así como sobre la conveniencia de su utilización, como un criterio de ponderación, proporción o, en su caso, flexibilización, a cargo de Jueces y Fiscales, siempre en el marco de la ley, parece conveniente acometer una serie de consideraciones finales sobre el «objeto» y los «sujetos» de la oportunidad, ya en el plano de la práctica procesal cotidiana.

\section{II. ÁMBITO DE APLICACIÓN}

En primer lugar, resulta, a todas luces, imprescindible precisar cual sea, en concreto, el objeto de la oportunidad, debido a la ausencia de una doctrina unívoca al respecto. Así, pues, hemos de concretar si la oportunidad se refiere, en exclusiva, conforme al parecer de los pioneros en su estudio, a la concesión, al Ministerio Fiscal, del poder de disposición sobre el ejercicio y mantenimiento de la pretensión penal o ha de incluirse, dentro de su ámbito de aplicación, tal y como apuntan algunos autores modernos, instituciones o mecanismos tales como la conformidad, la mediación o la concesión, al Poder Judicial, de una aplicación alternativa -en el marco del proceso- a la imposición de la sanción penal y su posible sustitución por otra suerte de medidas alternativas a la privación de libertad.

Parece razonable estimar, en sintonía la tesis mantenida por nuestra parte en trabajos anteriores a éste ${ }^{7}$, que tanto los órganos de enjuiciamiento, como los de la acusación y en cierta medida, los particulares -cada uno en el estricto ámbito de sus respectivas facultades y posibilidades procesales, so pena de incurrir en una «privatización» de la Justicia penal, mediante la inconveniente disponibilidad del objeto procesal penal- puedan, en los casos legalmente tasados al efecto -generalmente delitos de poca relevancia o de baja intensidad, a los que la doctrina suele referirse con la denominación de «delitos bagatela»-, y por razones de «oportunidad»-así, entre otras, la escasa lesión social, la inmediata reparación económica de la víctima, la evitación del contagio criminógeno, la pronta rehabilitación, readaptación o reeducación del delincuente-, acometer una barema-

${ }^{6}$ Para un estudio general sobre los principios que inspiran nuestros vigentes procesos judiciales, se remite al lector a CALAZA LÓPEZ, S., "Garantías constitucionales del proceso judicial español», Madrid, Ed. Colex, 2011.

7 Para un estudio específico sobre esta cuestión, vid., CALAZA LÓPEZ, S., «Las paradojas del mal llamado principio de oportunidad en el proceso penal», en prensa, 2012. 
ción, ponderación o proporción entre la legalidad y la justicia en el caso concreto.

En este sentido, y entroncando ahora con los «sujetos» legitimados para ejercer, en el ámbito de sus respectivas competencias, la oportunidad, resulta evidente afirmar, con PEDRAZ PENALVA, E. ${ }^{8}$, que «solo el órgano judicial, motivadamente, a través del oportuno proceso, y convencido más allá de toda duda razonable, es el competente para declarar la existencia del delito y la participación culpable del acusado, así como para imponerle la pena prevista en la ley material o, en su caso, para declarar la concurrencia de las circunstancias despenalizadotas de la norma penal sustantiva».

Es por ello por lo que la pretensión de atribución, al MF, en virtud del denominado "principio de oportunidad», de la facultad de no instar, de suspender o de poner término al proceso penal ha de asociarse, según este autor, con un supuesto de «desjudicialización» o de «no enjuiciamiento» de hechos que revisten caracteres de delito y no, desde luego, con una hipótesis de «despenalización». Y es que, en tal caso, no estaríamos, como resulta obvio, ante un supuesto en el que el Juez, en el marco del proceso judicial, decide concluir el proceso en atención a la apreciación de circunstancias despenalizadoras o, en su caso, a la conveniencia de conmutar la pena con alguna medida alternativa que resulte igualmente eficaz, al tiempo que menos gravosa, sino directamente ante el «no enjuiciamiento».

La determinación de cuáles sean, por lo demás, las actuaciones calificadas como típicas -en abstracto- en cada momento histórico, tan solo compete al Legislador y su concreción -o subsunción de esa norma al caso concreto- a los Jueces y Magistrados, en su función de juzgar y hacer ejecutar lo juzgado. De ahí que recientemente se haya estimado ${ }^{9}$, con todo acierto, que «no deben ser los órganos de persecución los que determinen la política criminal del Estado; quién debe determinarla son los órganos políticos: el legislador a través de la ley penal procesal y sustantiva, y el Ejecutivo dentro del ámbito de sus competencias para diseñar la estrategia del Estado para enfrentar el fenómeno delictivo».

8 Vid., PEDRAZ PENALVA, E. (Vid. Derecho Procesal Penal, Tomo I, Principios de Derecho Procesal Penal, Madrid, 2000, pág. 175.

9 Vid., RODRÍGUEZ GARCÍA, M. y CONTRERAS ALFARO, L. H., "Criterios de flexibilización en el ejercicio y sostenimiento de la acción penal. Notas en torno al principio de oportunidad como instrumento de política criminal», Diario La Ley ${ }^{\circ}$ 6255, 2005. 
Así, pues, los órganos de acusación tan sólo podrán dejar de de ejercitar o, en su caso, de mantener la pretensión penal cuando existan fundadas razones para estimar, a su juicio, tal y como acontece en la actualidad, la inexistencia del hecho, la ausencia de tipicidad o la imposible autoría, pero en modo alguno para convenir que ese hecho delictivo no merece ser perseguido, en atención a su «peculiaridad», "particularidad» o «excepcionalidad», conforme a un criterio subjetivo de «flexibilización», «relativización» o «moderación» de la Justicia penal.

El criterio de la «oportunidad» habrá, pues, de concretarse, en el ámbito subjetivo, en la figura de los Jueces y Magistrados -titulares, en exclusiva, del ejercicio de la acusación y del enjuiciamiento- dentro del proceso, así como en la de los particulares, cuando la Ley les confiera cierta posibilidad de disposición y, en el ámbito objetivo, en los delitos legalmente estipulados al efecto, por el Poder Legislativo, en tanto que único titular de la política criminal del Estado, sin que se produzcan, como consecuencia de una interferencia recíproca de roles, injerencias de uno en otro, tal y como acontecería si se facultase a los Jueces y Magistrados o, en su caso, a los Fiscales, para acometer, en el caso concreto, una «descriminalización» ad hoc de determinadas conductas legalmente típicas por razones de utilidad, celeridad, economía o modernización procesal.

Por último, hemos de afirmar, a modo de conclusión, que la «oportunidad» habría de definirse, en sentido estricto, conforme al estudio que hemos acometido al respecto, como la facultad, atribuida a los órganos de enjuiciamiento, de sustituir o conmutar -en los casos legalmente previstos- unas penas más radicales, por otras, igualmente eficaces, al tiempo que menos lesivas para los intereses de su autor, y ello en atención a la apreciación discrecional de circunstancias concretas que habrán de quedar, al propio tiempo, convenientemente motivadas.

La posibilidad de conferir, al Juez o Magistrado, la facultad de optar, con un amplio margen de discrecionalidad, dentro de los parámetros legalmente fijados y una vez concluido el proceso penal, con todas sus fases, entre la aplicación de una pena o su subsunción por una medida igualmente efectiva pero menos gravosa constituye, por lo demás, una medida positiva, especialmente si, con ello, se ha contribuido a aligerar el procedimiento, así como a procurar una pronta reeducación del delincuente, al tiempo que a otorgar una inmediata satisfacción económica, psicológica y jurídica a la víctima 


\section{REFLEXIONES GENERALES SOBRE LA CONVENIENCIA DE LA INSTAURACIÓN DE UNA JURISDICCIÓN VOLUNTARIA PENAL}

Nos preguntamos, finalmente, si sería factible la instauración de una Jurisdicción Voluntaria Penal, con la regulación de procesos caracterizados por las notas de agilidad, sencillez, flexibilidad, celeridad y ausencia de cosa juzgada, en aquellos supuestos de conflictos sociales de escasa o nula relevancia social, donde la controversia fuere menor o, incluso, dónde se previese y, por tanto, pudiese potenciar la «reconciliación» entre la víctima y el autor de los hechos. Los primeros serían susceptibles de resolución judicial en procesos ágiles, sencillos y ultra-rápidos, que, sin merma de garantías procesales, procurasen una pronta, aunque no definitiva, respuesta al conflicto social. Los segundos serían reconducidos a un jurista especialista en la mediación entre los sujetos implicados en este tipo de controversias de relevancia menor.

\section{En los procesos de naturaleza no jurisdiccional}

La resolución de un conflicto merced a la imprescindible intervención de un tercero, ajeno al Poder Judicial, sin el cual las partes nunca hubieren alcanzado un acuerdo o transacción, ha sido calificado, por un sector de nuestra doctrina procesal ${ }^{10}$, como una actuación ajena a la Administración de Justicia, a la que, por tanto, no puede, en modo alguno, definirse como «fórmula complementaria de resolución de conflictos».

Aún cuando partimos, en este epígrafe, de nuestra expresa adhe-

10 Vid., en este sentido, DE LA OLIVA SANTOS, A., cuando advierte que «no es cierto, desde ningún punto de vista, que la Administración de Justicia comprenda la mediación (ni otras fórmulas similares) y no es cierto, por tanto, que modernizar la Administración de Justicia suponga potenciar fórmulas complementarias de resolución de conflictos. La mediación no es Administración de Justicia, ni por sus protagonistas ni por su método. En la mediación no tiene por qué intervenir el Estado; puede llevarse a cabo con formas máximamente flexibles, simplemente amparadas por la Ley en cuánto manifestaciones de la autonomía de la voluntad de los sujetos jurídicos y el acuerdo se basa en la conveniencia mutua y no necesariamente en reglas jurídicas aplicables al caso. Por su parte, modernizar la Administración de Justicia es actuar sobre ella con propósitos de mejora y eso, dejando de lado elucubraciones de toda clase, significa idear y realizar mejoras orgánicas, procesales, humanas y materiales. No existe eso en el Proyecto de Ley de Mediación», en «Mediación y Justicia: síntomas patológicos», Otrosí no 8, octubre-diciembre, Ilustre Colegio de Abogados de Madrid, 2011, pág. 8 . 
sión a la reflexión recién explicitada, hemos de cuestionarnos, ello no obstante, si sería razonable, conveniente y posible, como «método alternativo» a la Administración de Justicia ${ }^{11}$, implantar, tomando como ejemplo la mediación civil y mercantil, a la que el Prof. de la Complutense se ha referido, un sistema de resolución de controversias penales de escasa, prácticamente nula, enjundia social. Y nos parece razonable que así sea siempre y cuando concurriesen las siguientes notas: en primer lugar, que la Ley Penal previese, de manera clara, explícita e inequívoca, con antelación al surgimiento del conflicto penal, cuáles fueren, exactamente, las actuaciones susceptibles de resolución voluntaria a través de la "mediación»; en segundo, que dichas «actuaciones» también pudieren, bajo el prudente arbitrio de los acusadores, público y privado, ponerse en conocimiento de los Tribunales de Justicia, de suerte que la elección entre uno u otro método de resolución de conflictos correspondiese, siempre y en todo caso, bien a la correspondencia o concurrencia de voluntades de sendas partes acusadoras, o bien al manifiesto «desinterés» de la acusación privada en perseguirlas; en tercero, que los «mediadores» fueren, siempre y en todo caso, profesionales del Derecho especializados en la materia, que pudieren garantizar la debida observancia de las normas jurídicas que tutelan los derechos e intereses susceptibles de negociación; y en cuarto, que la transacción, negociación o acuerdo fuere susceptible de ulterior revisión judicial, caso de disconformidad posterior, por alguna de las partes, bien motivada por el incumplimiento con los términos del acuerdo adoptado, bien por la mera insatisfacción ante el deficiente resultado obtenido tras su cumplimiento. Todo cuánto acaba de describirse nos recuerda, inevitablemente, a los procesos no jurisdiccionales de la Jurisdicción Voluntaria, caracterizados, precisamente, por todas las notas de inmediatez, simplificación, celeridad, y ausencia de cosa juzgada.

En sintonía con los procedimientos no jurisdiccionales de la nueva Jurisdicción Voluntaria Civil ${ }^{12}$, nos preguntamos si, en efecto,

11 Vid., BUITRÓN BALIÑA, P., quién, tras mostrar las limitaciones y dificultades de la introducción de la mediación en el proceso penal, concluye su análisis con la siguiente afirmación: «creo que solo un estudio riguroso desde el punto de vista jurídico y presupuestario nos aclararía si sería un mecanismo eficaz para contribuir a un mejor sistema de justicia penal, y no solo para reducir el número de asuntos pendientes en dicho orden jurisdiccional», «La mediación penal», en «Los retos del Poder Judicial ante la sociedad globalizada», Universidad de La Coruña, 2012, pág. 49.

12 Para un estudio pormenorizado y de conjunto sobre la nueva «Jurisdicción Voluntaria», se remite al lector al máximo exponente en la materia, FERNÁNDEZ DE BUJÁN, A., «La Jurisdicción Voluntaria en el plató», Revista del Colegio Notarial de Madrid n ${ }^{\circ}$ 41, enero-febrero, 2012. 
sería posible, instaurar en nuestro vigente ordenamiento procesal, una Jurisdicción Voluntaria Penal, merced a la cual, pudiera otorgarse, a un operador jurídico, distinto al órgano de enjuiciamiento, la solución del conflicto penal, mediante una "privatización» de nuestra Justicia penal, en los casos de faltas y delitos de baja intensidad o escaso reproche social.

La posibilidad de que un tercero, ajeno al conflicto, intervenga en la resolución del mismo, para ponerle término, podría equipararse, en efecto, en el ámbito penal, con los nuevos procedimientos de Jurisdicción Voluntaria de naturaleza no jurisdiccional, que integrarán, en un futuro inmediato, la nueva Ley de Jurisdicción Voluntaria ${ }^{13}$, dónde un operador jurídico distinto del Juez -generalmente, en los asuntos civiles, el Notario o el Secretario judicial- ofrecerán una respuesta inmediata a los justiciables, coadyuvando con ello a la descarga de trabajo del Poder Judicial.

La "descriminalización» de determinadas actuaciones penales, de escasa o nula relevancia social, a cargo del Legislativo, y la regulación de su posible resolución por mediación de operadores jurídicos especialmente cualificados, en procesos alternativos a los judiciales, dónde se alcanzasen «acuerdos» «negociaciones» o "transacciones», debidamente supervisadas y susceptibles de ulterior control judicial, no conllevaría interferencia alguna ente el Legislativo y el Judicial, ni supondría quiebra alguna del principio de legalidad, al tiempo que minimizaría las eventuales posibilidades de discriminaciones, desigualdades y abusos que toda conciliación ajena a los debidos controles pudiera conllevar.

La solución del conflicto penal, en un proceso de mediación, informado por los principios -apuntados por la doctrina penal mejor conocedora del estado de la cuestión en el plano de la práctica ${ }^{14}-$ de voluntariedad, gratuidad, confidencialidad, oficialidad (inicio por decisión judicial), flexibilidad y bilateralidad, supone, por lo demás,

13 Para un estudio pormenorizado sobre la Jurisdicción Voluntaria, se hace obligado consultar la obra de FERNÁNDEZ DE BUJÁN, A., Vid., entre otras, las siguientes monografías: Jurisdicción y arbitraje en Derecho Romano», Ed. Iustel, $1^{a}$ ed., Madrid, 2006; «Hacia una Teoría general de la Jurisdicción Voluntaria», volumen I, Ed. IUSTEL, Madrid, 2007; «Hacia una Teoría general de la Jurisdicción Voluntaria», volumen II, Ed. IUSTEL, Madrid, 2008.

14 Vid., esta enumeración de principios, en RÍOS MARTÍN, J., "Conclusiones del curso La mediación civil y penal. Dos años de experiencia. II parte del curso sobre alternativas a la judicialización de los conflictos dirigidos a jueces de familia y penales», Estudios de Derecho Judicial n ${ }^{\circ} 136$, Consejo General del Poder Judicial, Madrid, 2008. 
sin duda alguna, un avance en la represión de la delincuencia de leve, matizada o moderada gravedad.

Es por ello por lo que parece positivo, siempre en el marco legal, que determinados tipos de conflictos penales puedan ser rápidamente resueltos por las partes, merced a la intervención de un tercero imparcial, en aras de una consecución más rápida y efectiva de la paz social $^{15}$.

\section{En los procesos de naturaleza jurisdiccional}

Asimismo, hemos de preguntarnos, en los procedimientos de naturaleza jurisdiccional, si cabría, en virtud del supuesto «principio de oportunidad» otorgar a los órganos de enjuiciamiento la facultad discrecional de sustituir, conmutar o, de cualquier forma, suplir una pena por otra, en aras de una mayor eficacia, agilidad, humanidad, flexibilidad y economía procesal, en ciertos tipos de faltas y de delitos bagatela.

La regulación ex novo de procesos voluntarios penales, de naturaleza jurisdiccional, tomando como modelo los procesos voluntarios civiles, en -los que se admite, sin ningún género de duda, la «oportunidad», tanto en el ejercicio de la acción, como en el mantenimiento de la pretensión, debido, de un lado, la titularidad exclusiva de las partes implicadas en ese concreto proceso y, de otro, a la naturaleza privada del derecho, bien o interés jurídico protegido ${ }^{16}$ - nos parece muy pertinente.

15 Vid., un estudio sobre propuestas técnicas vinculadas a la mejora del modelo de mediación y de su aplicación como procedimiento complementario y extrajudicial de resolución extrajudicial de conflictos que deparen la mayor eficacia posible, MARTÍN DIZ, «Retos de la mediación como complemento al proceso judicial en una sociedad globalizada», en "Los retos del Poder Judicial ante la sociedad globalizada», Universidad de La Coruña, 2012, especialmente, págs. 144 a 146.

16 Vid., a propósito de la necesaria existencia de estos dos tipos de procesos, civil y penal, en función de la distinta naturaleza de los intereses que han de protegerse en cada uno de ellos, MONTERO AROCA, J., cuando afirma que «frente a un proceso necesario, en el que por tratarse de intereses públicos el principio de necesidad determinará su nacimiento y contenido, ha de existir otro proceso, en el que, por tratarse de intereses privados, la voluntad de las partes es el elemento determinante tanto de su nacimiento como de su contenido y de su extinción. Estos dos modelos básicos se corresponden con el proceso penal y civil; en el primero predomina el interés público, siendo su realización necesaria; en el segundo lo determinante para la iniciación del mismo es la voluntad del individuo, el cual, atendiendo a razones de oportunidad, acudirá o no al proceso para la defensa de sus intereses», en «Los principios políticos de la nueva Ley de Enjuiciamiento Civil. Los poderes del Juez y la oralidad», Ed. Tirant lo blanch, Valencia, 2001, págs. 60 y 61. 
En este sentido, los procesos voluntarios penales de naturaleza jurisdiccional, dónde el Juez sería el único operador jurídico destinado a emitir un «juicio» sobre el conflicto penal, se distinguirían de aquellos otros procesos penales voluntarios que carecen de dicha naturaleza, dónde otros profesionales, distintos a los Jueces, podrían ser llamados a resolver, a modo de «mediadores» ciertos otros conflictos sociales, por razón de factores tales como la entidad del bien jurídico protegido, la alarma social generada, así como de la intensidad de la lesión producida.

Corresponderá al Legislador, como es natural, por razones de «política criminal» seleccionar qué tipo de actuaciones serán susceptibles, en este tipo de procesos voluntarios, de ser resueltas, siempre y en todo caso, por los Jueces, debido a la «reserva jurisdiccional ${ }^{17}$, y cuáles, sin embargo, por otros profesionales. Los procesos de jurisdicción voluntaria penal de naturaleza jurisdiccional, que pudieran dirimir los conflictos penales legalmente estipulados -así, los delitos de mediana entidad, especialmente recurrentes, que afectasen, fundamentalmente, a intereses particulares, como podrían serlo, entre otros, a modo de ejemplo, los delitos contra el patrimonio, efectuados sin violencia- ofrecerían, como es lógico, la ventaja de la celeridad, flexibilidad, economía, inmediatez y eficacia en la búsqueda de la «verdad material», sin pérdida de garantías procesales.

Y es que no debe olvidarse, pese a las razones de depuración, descompresión y descongestión del sistema, -inspiradoras e instigadoras de la necesaria reforma de nuestro vigente proceso penal-que la finalidad del proceso penal, tal y como se ha advertido hasta la saciedad, no es otra que la «búsqueda de la verdad material» y este noble objetivo se desvirtúa y, en ocasiones, hasta se pierde con la asunción de todas las «alternativas» propuestas al proceso judicial penal tradicional, a excepción de la consistente en la creación un proceso penal voluntario, dónde, con todas las características que adornan aquellas medidas alternativas -implantación de la «oportunidad» del MF, la negociación, la mediación, etc.-, como lo son, entre otras, la flexibilidad, la celeridad, la economía y la humanidad, pudiera, al

17 Y ello en sintonía con la futura Ley de Jurisdicción Voluntaria, dónde, según expresa uno de sus autores más destacados, FERNÁNDEZ DE BUJÁN, A., «la desacertada equiparación de competencias en materia de JV hubiere implicado un estéril y artificioso reduccionismo de la JV al ámbito negocial y administrativo», resultando, en consecuencia, primordial la "redistribución de competencias» entre los actos de JV que tiene naturaleza jurisdiccional y los demás actos de JV, en FERNÁNDEZ DE BUJÁN, A., «La Jurisdicción Voluntaria en el plató», Revista del Colegio Notarial de Madrid n ${ }^{\circ} 41$, enero-febrero, 2012, pág. 26. 
propio tiempo, alcanzarse la verdad material. Nada obstaría, por lo demás, para que el Juez, una vez declarada la «culpabilidad» del autor de la ofensa, en un proceso más ágil, sencillo y rápido, que el convencional, pudiese, merced a criterios de "oportunidad reglada», a instancia del MF, o incluso, de la acusación particular -satisfecha con el desarrollo del proceso- conmutar la pena por una medida menos gravosa, al tiempo que igualmente efectiva.

\section{BIBLIOGRAFÍA}

BUITRÓN BALIÑA, P., «La mediación penal», en «Los retos del Poder Judicial ante la sociedad globalizada», Universidad de La Coruña, 2012.

CALAZA LÓPEZ, S.,

- «De la arbitrariedad administrativa, con especial referencia al ámbito penal», Madrid, Revista de Derecho, UNED, núm. 4, 2009

- «Recepción de la noción arbitrariedad en la Jurisdicción contencioso-administrativa española», Madrid, Revista de Derecho UNED n ${ }^{\circ}$ 7, 2010.

- «Garantías constitucionales del proceso judicial español», Madrid, Ed. Colex, 2011.

- ¿Es realmente un principio la oportunidad?, Actualidad Jurídica Aranzadi n842, mayo, 2012.

- «Las paradojas del mal llamado principio de oportunidad en el proceso penal», en prensa, 2012.

DE LA OLIVA SANTOS, A., «Mediación y Justicia: síntomas patológicos», Otrosí no 8, octubre-diciembre, Ilustre Colegio de Abogados de Madrid, 2011.

FERNÁNDEZ DE BUJÁN, A.,

- Jurisdicción voluntaria en Derecho Romano, Ed. Reus, Madrid, 1986 y 1999.

- La Jurisdicción Voluntaria (en el Derecho Procesal Español), Ed. Thomson-Civitas, Pamplona, 2001.

- Jurisdicción y Arbitraje en Derecho Romano, Ed. Iustel, Madrid, 2006.

- Hacia una teoría general de la Jurisdicción Voluntaria, Tomo I, Ed. Iustel, Madrid, 2007. 
- Protección Patrimonial de personas con discapacidad y Jurisdicción Voluntaria, Editorial Tirant lo Blanch, Valencia, 2007.

- Hacia una teoría general de la Jurisdicción Voluntaria, Tomo II, Ed. Iustel, Madrid, 2008.

- «Jurisdicción Voluntaria: Dar a cada uno lo suyo». Revista Registradores, n. 62, marzo- abril.

- «Jurisdicción Voluntaria». Tercera de ABC, 9 enero 2012.

- «Convención de 2006 sobre los derechos de las persona con discapacidad y proceso de incapacitación», Revista Icade, Universidad Pontificia de Comillas, septiembre-diciembre de 2011.

- «Incapacitación y Discapacidad». Tratado de Derecho de Familia. Capítulo VII. Tompson-Aranzadi 2012.

- «Xurisdicción voluntaria : una reforma lexislativa pendente para a nova lexislatura», núm. 41 de la Revista Galega de Administración Pública, REGAP, n. 41, xaneiro-xuño 2011.

- «La Jurisdicción Voluntaria en el plató». El Notario del Siglo XXI. Número 41 Enero-Febrero 2012.

- «Capacidad. Discapacidad. Incapacitación. Modificación judicial de la capacidad», Revista Jurídica de la Universidad Autónoma de Madrid (RJUAM), n 22, 2011.

- «Jurisdicción voluntaria: rectificar es de sabios», en El Notario del siglo XXI, no 31, mayo-junio 2010, Madrid.

- «El papel de la buena fe en los pactos, arbitrajes y contratos», en Anuario de Justicia Alternativa. Derecho Arbitral, Tribunal Arbitral de Barcelona, $\mathrm{n}^{\circ}$ 10, 2010.

- «Dos reformas legislativas pendientes: La Oficina Judicial y la Jurisdicción voluntaria», Publicaciones de la Real Academia de Jurisprudencia y Legislación: Problemas actuales de la Jurisdicción, II, 2010.

- «Observaciones al Proyecto de ley de implantación de la Nueva Oficina Judicial», Economist \& Jurist, Madrid, 2010.

- «La nueva Oficina Judicial», El Notario del siglo XXI, $\mathrm{n}^{\circ} 24, \mathrm{Ma}-$ drid, marzo-abril de 2009.

- «El necesario debate sobre el nuevo modelo de Oficina Judicial», Diario La Ley, 8 de junio de 2009.

- «El nuevo modelo de oficina judicial», Estudios en homenaje a 
Mercedes Gayosso y Navarrete, México, noviembre de 2009, págs. 693-706. 14. Id., «La hora de la Justicia», Estudios en homenaje al Prof. Elías Díaz, RJUAM, n 19, Madrid, 2009.

- «La Jurisdicción Voluntaria: En busca del tiempo perdido», Revista Jurídica Registradores, Madrid, enero de 2008.

- «Fundamentos históricos del arbitraje moderno», El Notario del siglo XXI, $\mathrm{n}^{\circ} 20$, Madrid, julio-agosto de 2008.

- «Protección de las personas vulnerables: la atención a situaciones de incapacidad, dependencia y vulnerabilidad y procedimientos de Jurisdicción Voluntaria» (Ponencia presentada en los Cursos de Verano de la Universidad Menéndez Pelayo (UIMP) Organizado por el Consejo General del Notariado en agosto de 2007), La defensa Jurídica de las Personas Vulnerables, Thomson-Civitas, Santander, 2008.

- «Procura y Reformas Legislativas», Revista del Consejo General de Procuradores, $\mathrm{n}^{\circ}$ 77, diciembre de 2008.

- «Proyecto de Ley de Jurisdicción Voluntaria» (I y II), Economist \& Jurist, $\mathrm{n}^{\mathrm{o}} 106$, diciembre-enero de 2007, págs. 100-105; y nº 107, febrero de 2007.

- «El Notario como órgano de la Jurisdicción Voluntaria», El Notario del Siglo XXI, 11, Madrid, Enero-Febrero de 2007.

- «El procedimiento general aplicable a Jueces y Secretarios Judiciales en el Proyecto de Jurisdicción Voluntaria de 2006», Revista de la Facultad de Derecho de la Universidad de Fortaleza, Brasil, 2007.

- «La Jurisdicción Voluntaria en el marco del Estado Constitucional de Derecho», El Notario del Siglo XXI, 11, Madrid, julio-agosto de 2007.

- «La Jurisdicción Voluntaria en Las Cortes Generales», Diario La Ley, 16 de octubre de 2007.

- «Esperando a la Jurisdicción Voluntaria», en Diario $A B C, 11$ de diciembre de 2007.

- «La administración de Justicia: órganos jurisdiccionales y judiciales», Revista Latinoamericana de Derecho Romano, Buenos Aires, 2007 (también en Revista General de Derecho Romano http://iustel.com $(R G D R), \mathrm{n}^{\mathrm{o}} 6$, junio, 2006)

- «Notariado y Jurisdicción Voluntaria», RJUAM, 15, 2007. 
- «Documentación y Notariado en Derecho Romano», Studia et Documenta Historiae et Iuris (SDIH), Roma, 2007.

- «Reflexiones a propósito del Anteproyecto de ley de jurisdicción voluntaria de 2005", In onore de Luigi Labruna. Fides. Humanitas. Ius, MMVII, Editoriale Scientifica, Napoli.

- «El nuevo perfil de la Jurisdicción voluntaria en el Anteproyecto de Ley de Octubre de 2005», en Diario La Ley, 8 de junio de 2006.

- «El anteproyecto de Jurisdicción Voluntaria de Junio de 2006», El Notario del siglo XXI, VIII, Madrid, julio-agosto de 2006.

- «Observaciones al proyecto de Ley de jurisdicción Voluntaria, de octubre de 2006» I y II, en Diario La Ley, 27 y 28 de noviembre de 2006.

- «La nueva configuración de la jurisdicción voluntaria en el Anteproyecto de Ley de junio de 2006», Otrosí. Revista del Colegio de Abogados de Madrid, Madrid, diciembre de 2006.

- «La Jurisdicción Voluntaria: una reforma legislativa pendiente», Anales de la Academia Matritense del Notariado, Madrid, 2006.

- «La Reforma de la Jurisdicción Voluntaria: problemas, interrogantes, soluciones.», en Diario La Ley, 23 de marzo de 2005 (también en $R G D R \mathrm{n}^{\circ} 5$, diciembre 2005).

- «El problema de la naturaleza jurídica de la jurisdicción voluntaria a la luz de la experiencia histórica», en $R G D R, \mathrm{n}^{\circ} 5$, diciembre de 2005.

- «La hora de la Jurisdicción Voluntaria». Estudios Homenaje a Rodríguez, Mourullo, 2005.

- «Jurisdicción Voluntaria: perspectivas de futuro», Estudios Homenaje a Manuel Albaladejo, 2005.

- «Contribución al estudio histórico-jurídico del arbitraje», Anuario de Justicia alternativa. Derecho arbitral, Barcelona, 2005.

- «La Jurisdicción Voluntaria: Problemas, Interrogantes y Soluciones», Estudios en homenaje al Prof. Franciosi, Saturas Editrice, Nápoles, 2005.

- «La reforma de la jurisdicción voluntaria», Otrosí. Revista del Colegio de abogados de Madrid, Madrid, septiembre de 2005.

- «Los profesionales del derecho y la jurisdicción voluntaria. Ponencia General presentada en el XVII Congreso Nacional de Pro- 
fesores de Derecho Romano de la República Argentina, General Roca, La Patagonia», Revista de la Asociación de Derecho Romano de Argentina, La Patagonia, Argentina, 2005.

- «La protección patrimonial de los discapacitados y la jurisdicción voluntaria a la luz de lo previsto en la Ley 41/2003, de 18 de noviembre, Ponencia presentada en el II Congreso Regional sobre Protección Jurídica del Discapacitado», Protección Jurídica del Discapacitado. II congreso Regional, Ed. Tirant lo Blanch, Burgos, 2007.

- «Reflexiones sobre el Anteproyecto de la Ley de Jurisdicción Voluntaria», Homenaje al Prof. González Campos, RJUAM, 13, Madrid, 2005.

- «A propósito de la competencia en materia de iurisdictio voluntaria en Derecho Romano", Revista de Derecho Notarial y A.A.M.N., T. XXVIII.

- «La reforma legislativa de la jurisdicción voluntaria: reflexiones de presente y perspectivas de futuro", Derecho de los Negocios, n. ${ }^{\circ}$ $163,2004$.

- «Jurisdicción Voluntaria: Historia (I), Problemas (II), Interrogantes (III) y Soluciones (IV)», Tribuna Pública, Mercados, Voz de Galicia, 12-09; 17-09; 26-09; 3-10-2004.

- «Carácter contractual del arbitraje», Anuario de Justicia alternativa. Derecho Arbitral, Barcelona 2004.

- «El procedimiento de Jurisdicción Voluntaria», Derecho y Negocios, Madrid, 2004.

- «La sanción constitucional de la jurisdicción voluntaria», Derecho y Negocios, Madrid, 2004.

- «Contribución al estudio histórico del arbitraje», Revista Jurídica de la UAM, número 8, Madrid, 2003, Homenaje a D. Aurelio Menéndez.

- «De los arbitria bonae fides pretorios a los iudicia bonae fidei civiles», Convengo internazionale de studi in onore del profesor Alberto Burdese, Padova 2003, vol.2.

- «Testigos y documentos en la práctica negocial y judicial romana», en Ivra, Revista Internazionale di Diritto Romano e Antico, vol. 54, 2003. (También en RGDR, $\mathrm{n}^{\circ}$ 4, 2005; y en RJUAM, Revista Jurídica de la Universidad Autónoma de Madrid, 12, 2005) 
- «Anteproyecto de jurisdicción voluntaria», Ilustre colegio de Abogados de Lugo, Lugo, 2002.

- «La jurisdicción voluntaria: racionalización y redistribución de competencias», Libro Homenaje a Sánchez Mera, Madrid, 2002.

- «La Jurisdicción Voluntaria: una reforma legislativa pendiente», Estudios Jurídicos, Ministerio de Justicia, vol. IV, 2002.

- «Noción de iurisdictio y etapas. Jurisdicción contenciosa y jurisdicción voluntaria», en Bases de Conocimiento Jurídico, Derecho Romano, http://www.iustel.com, PortalDerecho, 2002.

- «Arbitraje», en Bases de Conocimiento Jurídico, Derecho Romano, http://www.iustel.com, PortalDerecho, 2002.

- «Consideraciones de lege ferenda en materia de jurisdicción voluntaria y Anteproyecto de Jurisdicción Voluntaria», Revista del Colegio de abogados de Lugo, 2001, págs. 22-24 y 2002.

- «Los principios informadores de la jurisdicción voluntaria: una propuesta de futuro», Anuario de Derecho de la U.A.M., vol. 3, 2001.

- «Jurisdicción Voluntaria: naturaleza jurídica y diferencias de procedimiento con la jurisdicción contenciosa» (I y II), Actualidad Civil, n. ${ }^{\circ} 36,2001$, págs. 1277-1316 y n. ${ }^{\circ} 37$.

- «Fides publica e instrumenta publice confecta en Derecho romano», Revista de Estudios Latinos, Madrid, 2001.

- «La jurisdicción voluntaria en la encrucijada: su conexión con el nuevo modelo procesal de la LEC del año 2000», Derecho y Opinión, Córdoba, 2000.

- «A propósito de la competencia en materia de «iurisdictio voluntaria» en Derecho Romano", Revista de Derecho Notarial, Anales de la Academia Matritense del Notariado, CXXXI, Madrid, 1996.

- «Consideraciones acerca del carácter clásico y jurisdiccional de la denominada por Marciano "Iurisdictio voluntaria», en D. 1.16.2.pr.», Estudios Homenaje a Juan Iglesias, Madrid, 1988.

- «Elenco de manifestaciones de iurisdictio voluntaria en Derecho clásico y en la praxis postclásica», Revista de Historia de Derecho Húngaro, Budapest, 1988.

- «Diferencias entre los actos de iurisdictio contenciosa y iurisdictio voluntaria en Derecho Romano», Estudios Homenaje a A. D'Ors, vol. I, Pamplona, 1987. 
GIMENO SENDRA, V., «Los procedimientos penales simplificados. Principio de oportunidad y proceso penal monitorio», Poder Judicial, $\mathrm{n}^{\circ}$ especial II, Madrid, 1988.

MARTÍN DIZ, «Retos de la mediación como complemento al proceso judicial en una sociedad globalizada», en "Los retos del Poder Judicial ante la sociedad globalizada», Universidad de La Coruña, 2012.

MONTERO AROCA, J.,

- «Principios del proceso penal. Una explicación basada en la razón», Ed. Tirant lo blanch, Valencia, 1997.

- «Los principios políticos de la nueva Ley de Enjuiciamiento Civil. Los poderes del Juez y la oralidad», Ed. Tirant lo blanch, Valencia, 2001 .

MORENO CATENA, V.,

- «El proceso penal español. Algunas alternativas para la reforma», en «Sistemas penales europeos», Cuadernos de Derecho Judicial, Consejo General del Poder Judicial, Madrid, 2002.

- «El principio de oportunidad en España», Congreso internacional sobre el principio de oportunidad en materia penal, Colegio de Abogados de La Plata, 2004.

PEDRAZ PENALVA, E., Derecho Procesal Penal, Tomo I, Principios de Derecho Procesal Penal, Madrid, 2000.

RÍOS MARTÍN, J., "Conclusiones del curso La mediación civil y penal. Dos años de experiencia. II parte del curso sobre alternativas a la judicialización de los conflictos dirigidos a jueces de familia y penales», Estudios de Derecho Judicial $\mathrm{n}^{\circ}$ 136, Consejo General del Poder Judicial, Madrid, 2008.

RODRÍGUEZ GARCÍA, M. y CONTRERAS ALFARO, L. H., «Criterios de flexibilización en el ejercicio y sostenimiento de la acción penal. Notas en torno al principio de oportunidad como instrumento de política criminal», Diario La Ley n 6255, 2005. 
